\title{
SOCIAL WORKERS' ATTITUDES TOWARDS PUBLIC ACCOUNTABILITY
}

Kyu-taik Sung*

\begin{abstract}
The public demand for accountability of human services has been increasing in the United States. Despite the growing importance of public accountability as a special responsibility of social workers, little information is available in U.S. on how these pro. fessionals react to the implementation of accountability programs.

The survey reported in this paper was made to explore the attitudes of social workers in U.S. hospitals toward PSRO, a nationwide health care service review system. The paper presents a descriptive overview of significant aspects of American social workers' personal attitudes toward various issues of current concern about this accountability system.
\end{abstract}

\section{Introduction}

$I^{N}$ N U.S., Federal control in the area of human services has been expanding as Federal expenditures for the nation's health and social services are steadily increasing. Consequently, the public demand for accountability of human services has been growing.

In response to this, a number of human service agencies in U.S has undertaken certain activities for the development and utilization of accountability programmes. Such activities are increasingly more visible, particularly in the health care setting. ${ }^{1-5,11}$ By far, the most significant action taken in U.S. in the area of health care has been the establishment of Professional Standards Review Organizations (PSROs), a nationwide health care service review system. ${ }^{6-8}$
The PSRO system was mandated for physicians in the 1972 Amendments to the U.S. Social Security Act, involving practising physicians in the on-going review and evaluation of their colleagues' health care services which are reimbursed by the Federal Government via its health-care insurance programmes: Medicare, Medicaid, and the Maternal and Child Health Programme.

The basic purpose of the PSRO system is to confirm that these Federally-funded health care services are of a quality that meets professionally-recognized standards of care, medically necessary, and appropriately provided in the most economical settings. Thus, PSRO's three components - utilization review, peer review, and medical care review - are geared to analyze and evaluate the quality and cost dimensions of the health care services, Currently review of

* Visiting Scholar, The Rackbam Graduate School, The University of Michigan; Professor of Social Work, Yonsei University, Seoul, Korea.

The author is grateful to the directors of the social service departments of the hospitals which participated in this study and to $B$ ob. Bixby for his cooperation in the early phase of this study. 
the services given to hospital patients is the most important responsibility of the PSRO accountability system.

PSRO is the backbone of the mandate to account for activities of non-physicians; the system poses a challenge for social workers in health care as well. Now social workers in hospitals are directly and fully involved in the utilization of the PSRO accountability system. Under this system, they have begun to play a more prominent and essential role in hospitals. They have broadened the perspective of accountability so that it is focused not only on health care service within the hospital but also on services to the patient's family and community outside the hospital.

PSRO is a symbol of the public chalienge to health professionals. The social work profession, however, worked toward inclusion of social work in the PSRO system and embraced the system as a significant mechanism for enhancing the credibility of the profession..$^{9-11}$. Thus, an opportunity has been brought to social workers to take a greater share in the responsibility for provision of high quality health care services. And, today, in a comprehensive health care programmes in U.S., social work takes part as one of medical care services. ${ }^{12}$

However, a concern to those in social work is to what extent the existing roles and values of social workers are compatible with this accountability system which has been imposed on them by public..

This paper, based on a survey of hospitalbased social workers in U.S., explores the impact of the PSRO accountability system on social workers, in terms of their attitudes toward specific issues of their concern regarding the system.
The attitudes of social workers, or users of the accountability system, was considered to comprise an important part of the implementation of the systern, because a user who dislikes or distrusts an accountability system can undermine that system. Human service programmes resisted by programme users were seen to fail and those distrusted by the users were not effectively implemented. ${ }^{13} \mathrm{It}$ would seem worthwhile, therefore, to study the attitudes and correlates of these attitudes.

\section{Method}

Indicators of attitudes were derived from several issues of importance to social workers that grow out of their professional values and which are likely to affect their attitudes toward the accountability system. Multiple indicators were used to obtain a more reliable representation of attitude. The selection of 20 attitudinal items involved consultation with social workers from two different hospitals. Responses to a 20 item questionnaire, which was given as a pretest to 22 social workers at the two hospitals, helped to eliminate several questions. Finally 15 items were selected (Table 1). Sample question: "To what extent do you feel professional autonomy is preserved under the PSRO system?" Answer : I feel autonomy is preserved : (1)...to a very little extent; (2)... to a little extent; (3) .... to some extent; (4).... to a great extent, (5) ... to a very great extent.

The study has a sample population which consisted of 124 social workers serving at 15 general hospitals selected at random from 45 hospitals in South Michigan in Midwest, where about 70 percent of Michigan hospitals are located. The hospitals had social service departments and had been operating the PSRO system. All social workers in direct service at the hospitals 
were asked to complete the 15 -item questionnaire at their convenience without signing their name, and to return it to the researcher by mail. There were $106(85 \%)$ usable returns.

On the whole, the characteristics of respondents were similar. At each hospital, two-thirds of the social workers were remale and about 70 percent had an MSW degree. One half of them were certified social workers. The mean age was 31 , and they had an average of five years of experience in social work, and had worked in their current hospital social services for an average of 3.5 years.

\section{Findings}

There were no overall differences at a statistically significant level among the 15 hospitals in terms of attitudinal ratings. In analysis of variance, the F-ratio on each attitudinal item fell short of a desired level of statistical significance. Characteristics of respondents that might be expected to affect attitude, such as sex, tenure, education, and certificate status, did not differentiate the attitudinal ratings at a statistically significant level.

Table 1 summarizes responses to the 15 items referring to social workers' attitudes toward or feelings on the accountability system.

Impact of Implementation: It has been unclear to what extent social workers are satisfied with the use of the accountability system. The findings of this study show that respondents were neither satisfied nor dissatisfied with the implementation of the accountability system.

Concerned persons within the social work profession hold a belief that, through the implementation of accountability programmes, the profession will be better recognized and social workers' performance will be enhanced. ${ }^{14-16}$ In this study, however, only 34 percent of the respondents positively felt FSRO enhanced their work performance.

There is also concern among social workers that PSRO's performance review reduces time for professional activities with the patient as it increases meetings and paperwork. Unexpectedly, however, only a quarter of the respondents saw PSRO definitely took away their work time.

Mean scores presented in the table provide additional information. The mean rating of the three items regarding the impact is 3.20 , or roughly 'to some extent' or 'medium'.

On Accountability Standards and Procedures: The accountability system is imposed on social workers by forces outside the profession. Therefore, it is important to see whether the users come to accept the concepts and goals of the system and are tolerant of the demands of standards and procedures set for implementation, including peer review and discharge planning.

Table 1 shows that respondents neither agreed nor disagreed with PSRO standards, the percentage distribution showing a roughly normal curve. However, peer review and particularly discharge planning elicited considerably negative feelings; half of the respondents expressed disagreement with these accountability procedures. The mean of the three items regarding standards and procedures is 2.77 or barely 'agree to some extent'.

Review Methods : Under the PSRO system, social workers are requested to record 
not cnly the process of their intervention but also the outcome of it in terms of objective and quantifiable criteria. This is a challenge for which many social workers are not yet well prepared. As shown in Table 1, the overwhelming majority of the respondents disagreed with evaluation of process and outcome, particularly the latter. Such strongly negative attitudes probably reflect the respondents' anxiety about and dissatisfaction with being reviewed or audit ed of their work performance by colleagues and administrators. On quantifiable evaluation criteria, 75 percent disagreed. (The quantifable criteria shown in the questionnaire included amount of time spent per client/case, distance travelled for service. cost per case, etc,). This reaction seems to reffect social workers' traditional concern with the qualitative aspect of their services. The overall rating of items regarding evaluation methods is 2.14 or agreeable to a little extent'.

Autonomy: A principal issue raised by PSRO is the autonomy of health professionals. Autonomy is a very sensitive issue for social workers practising side-by-side with the dominant profession of medicine. Only a quarter of the respondents felt autonomy was preserved under the system, while 38 nercent felt it was not. Thus, the response was fairly negative. The mean rating of autonomy is 2.76 or barely within 'to some extent'.

Confidentiality: Confidentiality also emerges as a serious issue in any discussion of the accountability system. Confidentiality is the hallmark of social workers' professional relationshios with their clients. However, the system tends to generate dysfunctional consequences which threaten confidentiality, such as increased paperwork and the need to feed bureaucracies with ever greater amounts of information about practitioner performance. As expected, the majority of the respondents $(77 \%)$ felt confidentiality is not protected. Thus, the rating of confidentiality is only 2.12 or 'protected to a little extent'.

Administrative Support : In order to implement the complicated and demanding accountability system successfully, the users need adequate and timely support from the administration, including information. personnel, incentives, etc. Table 1 summarizes the responses on the items pertaining to support received from the hospital administration. About 30 percent of the respondents were not informed about the system and nearly a half of them were not informed about audit results of performance reviews. More than 40 percent were not assisted by supervisors in implementing the system. Responses to administrative support is 2.74 or barely within 'to some extent'.

\section{To Whom Do Social Workers Prefer to be}

Accountable? The entry of a third party, such as insurance carriers, into the health care field has aroused a great concern among American consumers of health care services over the issues of to whom the health care provider is more accountable. The social workers' reaction to this issue was checked in addition to queries on the 15 items.

Currently hospital-based social workers in U.S. face increasing demands for evaluative statements on their services from hospital administrators, physicians, social service directors, patients, third parties, professional organizations, PSROs or fellow social workers.

The respondents were asked to rankorder whom they felt they were currently accountable. They listed their response in the order shown in Table 2. However, 
when asked to order to whom they would prefer to be accountable, they changed this order. The social workers preferred to be accountable to the patient or the client. They preferred their social service director, their immediate supervisor, next to the client. Peer and physicians were ranked about equally near the middle level in preference. Third parties and PSROs were rated the lowest.

\section{Conclusion and Discussion}

The social workers agreed with the accountability system only to some extent. There seemed to be an undercurrent of hesitancy among the professionals to embrace the accountability system. ${ }^{17,18}$ Their reactions to several important queries were lukewarm if not unenthusiastic.

PSRO has institutionalized the peer control function of health professionals. ${ }^{6,19}$ In the system, peer review is carried out by the professionals in the form of a formal review where on-going systematic surveillance of their colleagues' activities is required. The social workers' reaction to this formalized review procedures was considerably negative, suggesting their displeasure with the procedure enforced by the hospital, another type of 'bureaucractic' agency.

Currently a dominant emphasis of the American hospital is on discharge planning. ${ }^{20}, 21$ Hospital management, which is concerned with cost-efficiency, wishes to reduce revenue lost when patients stay beyond the predetermined length of hospital stay. (At the time of the admission to the hospital, the predicted length of stay is assigned based on data for the average length of stay for particular diagnoses. Stay beyond the validated period will not be paid by the funding source, e.g., PSRO and other insurance carriers, and the regulations provide that the hospital cannot bill the patient). Social workers, however, tend to view that their self-esteem and professional image are threatened by the implementation of discharge planning which, they believe, can be done by non-professionals. As expected, a half of the respondents expressed disapproval of their involvement in discharge planning. Although discharge planning did not seem to be a kind of service preferred by some social workers, it neverthless represents an important contribution to the welfare of the patient and the financial solvency of the hospital. A half of the respondents appeared to agree that the service is important.

The overwhelming majority of the respondents appeared to be reluctant to comply with the requirements set for the performance review, paricularly outcome evaluaticn and use of quantifiable evaluation criteria. This finding reflects the traditional concern of social workers with the qualitative aspect of their service, and reminds us of technical difficulties involved in quantifying the outcome of social work.

A principal issue raised by the accountability system is the autonomy of health professionals. Autonomy is a very sensitive issue to hospital-based social workers who have been trying for years to be recognized as full-fledged professionals. ${ }^{22,23}$ What comes into question is how valid are social workers' concerns regarding PSRO invasion of professional autonomy? Therefore, their reaction to professional autonomy draws our special attention.

Each PSRO or hospital can exercise a certain amount of discretion over the development of criteria for the quality of care, norms for the frequency and duration of 
services, and standands for the degree of compliance to PSRO requirements. Besides, PSRO has built into its system the peer review mechanism which is believed to be conducive to the assurance of both autonomy and accountability - the two essential elements of professionalism. ${ }^{24}$ From this standpoint, some critics argue that professional autonomy would not be significantly limited by PSRO. In this study, however, about 40 percent of the social workers did not feel autonomy was preserved under PSRO. Their concern over autcnomy seemed to be a lingering one.

Confidentiality has emerged as a serious issue in any discussion of the accountability system. A potential, in fact, exists for the abuse of the right of confidentiality of the professional-client relationship, since the third party or insurance carriers have access to these personal records. ${ }^{25}$ Unfortunately, demand for extensive information on service activities is likely to increase as the accountability system develops. As expected, the respondents reacted very negatively to the query on confidentiality.

Administrative support activities were rated fairly poorly. In particularly, the res. pondents felt they were not well informed about audit results and the administrator did not assist them well to implement the system. A lack of feedback on performance review could lead to difficulties in reorienting the users to effective utilization of the system. Administrators must systematically update the users with regard to audit results and provide them with adequate and timely support including incentives for the implementation of the new system.

As these findings suggest, the social workers were reluctant and unwilling to fully accept or comply with the accountability system. The entry of accountability programmes into the human service arena has apparently enlarged the existing source of strain between social work professionals and their bureaucratic agencies. The disagreement and reluctance shown by the respondents may reflect this type of strain.

An approach to reducing such strain would be redefining the situation so that the agency's accountability goals and the professionals' needs may be perceived, where possible, as congruent. 'This could be achieved in part by stressing mutually beneficial elements in the accountability system. At least two such elements might be considered here.

An important objective of an accountability programme, besides issues of quality and cost is to help the programme users to be aware of how they are doing their jobs, what mode of intervention is more or less effective, and how to plan for future services. The attainment of these objectives can raise the level of professional competency which the users aspire. This, in turn, would enable them to gain esteem from clients, recognition from colleagues, and confidence from management.

Social workers need to gain professional recognition in areas such as those of full acknowledgement of independent status by insurance carriers, inclusion in national health insurance plans, and deductability of payments made to social workers on Federal income tax. ${ }^{9,16}$ If social workers successfully establish and implement norms of diagnosis and treatment in compliance with the PSRO law, regulatory and financing institutions' respect for the professionals' credible status will increase. Thus, social workers can benefit from the implementa. tion of the accountability system. 
Successful implementation of the accountability system directly affects the hospital's ability to acquire resources for survival as well. Social workers must implement this system for the hospital, their employer. As stated in Code of Ethics of National Association of Social Workers, ${ }^{26}$ they have an obligation to adhere to commitments made to their employing agency. If they do not successfully implement the criteria, less relevant and less acceptable criteria may be imposed by PSRO and the public. Therefore, once the system is introduced into the hospital, social workers have the responsibility to learn about the system, develop modes of intervention that are conducive to the attainment of the system objectives, and contribute to the system's development.

Autonomy, confidentiality, and other diffculties described above may be resolved to a great extent, as the users become more accustomed and adjusted to the requirements of the accountability system, and as procedures and techniques for alleviating these difficulties are developed and effectively put into practice.

Despite the difficulties, the social workers were clearly committed to their clients. Hospital social workers have long been advocating on behalf of patients and their families. They have done much to protect the patient's rights to services available within and without the hospital. As suggested by the social workers' choice of the parties to which they prefer to be accountable, the professionals would hold onto this commitment.

As yet, there are technical problems that must be resolved in the categorization of process and outcome of social work service, the precise numerical statement of what constitutes optimally good service, and the operationalization of the efficiency aspect of the service. This must be done if the system is to achieve high technical quality.

In the operation of a successful accountability system, however, the management of the agency's human resources would also have to be considered. There are a large number of factors affecting the morale and satisfaction of the users which are within the reach of managerial personnel. User resistance, for instance, can result from the way the system is managed. Some of these factors include arranging good working conditions, giving chances for advancement and professional growth, treating grievances fairly, appreciating a job well done, and other leadership qualities. ${ }^{27,28}$ The hospital will bccome more dependent upon its manager's competence as it is thrust deeply into the accountability system.

The survey reported in this paper was done to explore social workers attitudes toward public accountability, about which little information was available. Implications of significant findings were discussed.

The social workers' fairly negative attitudes toward the accountability system warrant further investigation. Future study should focus on conditions conducive to positive user attitude, the possible effects of such attitude on the quality of the implementation of the accountability system, and the harmony of the user-enforcer relations.

As human service agencies receive more public funds, the public demand for accountability of their services will grow. To social workers, the demand represents a pressing and difficult challenge. And, this challenge is an expression of the sentiment and will of the American consumers. In 
U.S., the mere provision of the services to the client is no longer an acceptable justification of the value of the services. The quality and economy of the services must be demonstrated to the consumers and fund givers.

\section{REFERENCES :}

1. Chernesky, R. H, anl Lurie, A. "Developing A Quality Assurance Program," Health and Social Work, 1, 1 (1976), $117-130$

2. Ferguson, K., Bowden, M. L., Lachniet, D., Malcom, A., and Morgan, G. "Initiation of a Quality Assurance Program for Social Work Practice in a Teaching Hospital, ${ }^{;}$Social Work in Health Care, 2, 2 (1976), $205-217$.

3. Spano, R. M., Kiresuk. T. J. and Lund, S. H. "An Operational Model to Achieve Accountability for Social Work in Health Care," Social Work in Health Care, 3, 2 (1977), 123-141.

4. Berkman, B., and Rehr, H. "Social Work Undertakes Its Own Audit," Social Work in Health Care, 9 , 1 (1978), $273-236$.

5. Volland, P. "Social Work Information and Accountability Systems in a Hospital Setting," Social Work in Health Care 1, $3(1977), 27 \%-285$.

6. Decker, B., and Bonner, P. PSRO : Organization for Regional Peer Review. Cambridge, Mass, Ballinger, 1973.

7. Wayne, M. A. "PSRO : Issues in Health Care Policy," Health and Social Work, 2, 4 (1977), 26-49.

8. Reynolds, M. M. "Professional Review of Health Care Services." Health and Social Work, 1, 1 (1976), 39-60.

9. NASW, "Private Practice Group Studies Licensing and Insurance Provision," National Association of Social Workers News, May 1973, 2-3.

10. Rehr,H. "The Glimate is Set for Quality Assurance : Implications for Social Work," Rehr, H. (Ed.), Professional Accountability for Social Work Practice. New York, Prodist, 1979, 16-26.

11. Coulton, C. J. Social Work Quality Assurance Programs : A Comparative Analysis. Washington, D.C., National Association of Social Work, 1979.

12. Palmiere, D. "Expanding Role of Social Work in Medical Settings," in Trends in Social Work Practice and Knowledge, NASW: Tenth Anniversary Symposium. New York, National Association of Social Workers, 1966, 229-237.

13. Zaitman, G., Duncan, R, and Holbek, J. Innovations and Organizations, New York, Wiley, $1973,85-104$.

14. Hoshino, G. "Social Services: The Problem of Accountability," The Social Service Review, 47, 3 (1973), $373-393$.

15. Rosenberg, M. L, and Brody, R. "The Threat or Challenge of Accountability," Social Work, 19 , 3 (1974) 344350.

16. Westerman, J. H., Spano, R. M., and Keyes, M. A. "Public Accountability, Quality Assurance and Social Work," Social Work in Health Care, 2, 1 (1976), 33-42.

17. Sung, K. "Working under the Accountability System: A Study of the Reaction of Social Workers, "Administration in Social Work, 6, $4(1982), 15-30$.

18. Sung, K., and Katan, J. "Social Workers" Reactions to Accountability Programs : Sorne Implications," Journal of Applied Social Sciences, Forthcoming.

19. Chernesky, R. H. and Young, A. T. "Developing a Peer Review System," in Rehr, H. (Ed.), Professional Accoun" tability for Social Work Practice. New York, Prodist, 1979, 74-91.

20. American Hospital Association. Discharge Planning for Hospital Chicago, Author, 1974.

21. Rossen, S. "Discharge Planning - Social Workers Play an Important Role;" Social Work Administration, 3 , 5 (1977), $4-5$.

22. Caputi, M. A. "Social Work in Health Care : Past and Future," Health and Social Work, 3, 1 (1978), 9-29.

23. Hollowitz, E. "Trnovations in Hospital Social Work" Social Work, 17, 1 (1972), 89-97.

24. Freidson, E. Profession of Medicine. New York, Dodd and Mean, 1973.

25. Reid, W. J. "Developments the Use of Organized Data," Social Work, 19, 5 (1974), 585-393.

26. NASW. National Association of Social Workers Code of Ethics, Section IV, 1980.

27. Kadushin, A "Supervisor-Supervisee : A Survey," Social Work, 19, 3 (1974), 284897.

23. Tannenbaum, A., Weshler, I. R., and Massarik. F. Leadership and Organization : A Behavional Science Approach. New York, Columbia University Press, 1974, 88-90. 
Table 1. Ratings on Attitudinal Items

\begin{tabular}{|c|c|c|c|c|c|}
\hline & Item & posit & & $\begin{array}{l}\text { nega- } \\
\text { tive }\end{array}$ & Mean (s.d.) \\
\hline $\begin{array}{l}\text { Impact of } \\
\text { Implemen- } \\
\text { tation }\end{array}$ & $\begin{array}{l}\text { Are satisfied with implementation } \\
\text { Enhanced work performance } \\
\text { Did not lose work time }\end{array}$ & $\begin{array}{l}24 \\
34 \\
50\end{array}$ & $\begin{array}{l}51 \\
40 \\
35\end{array}$ & $\begin{array}{l}25 \\
26 \\
15\end{array}$ & $\begin{array}{l}2.94(.88) \\
3.11(.98) \\
3.56(1.14)\end{array}$ \\
\hline $\begin{array}{l}\text { Standards } \\
\quad \& \\
\text { Procedures }\end{array}$ & $\begin{array}{l}\text { Agree with standards } \\
\text { Agree with peer review } \\
\text { Agree with involvement in } \\
\text { discharge planning }\end{array}$ & $\begin{array}{l}32 \\
18 \\
21\end{array}$ & 40 & $\begin{array}{l}28 \\
46 \\
53\end{array}$ & $\begin{array}{l}3.03(.83) \\
2.68(.77) \\
2.61(.72)\end{array}$ \\
\hline $\begin{array}{l}\text { Review } \\
\text { Methods }\end{array}$ & $\begin{array}{l}\text { Prefer process evaluation } \\
\text { Prefer outcome evaluation } \\
\text { Agree to use quantifiable criteria }\end{array}$ & $\begin{array}{r}14 \\
9 \\
8\end{array}$ & $\begin{array}{l}19 \\
18 \\
17\end{array}$ & $\begin{array}{l}67 \\
73 \\
75 \\
\end{array}$ & $\begin{array}{l}2.30(.97) \\
2.11(.78) \\
2.02(.78)\end{array}$ \\
\hline Autonomy & Feel autonomy is preserved & 25 & 37 & 38 & $2.76(.88)$ \\
\hline $\begin{array}{l}\text { Confiden- } \\
\text { tiality }\end{array}$ & Feel confidentiality is protected & 6 & 17 & 77 & $2.12(.67)$ \\
\hline $\begin{array}{l}\text { Administ- } \\
\text { rative } \\
\text { Support }\end{array}$ & $\begin{array}{l}\text { Are informed about the system } \\
\text { Are informed about audit results } \\
\text { Are assisted by supervisor } \\
\text { Are supported by administration }\end{array}$ & $\begin{array}{l}35 \\
31 \\
34 \\
26\end{array}$ & $\begin{array}{l}36 \\
24 \\
24 \\
28\end{array}$ & $\begin{array}{l}29 \\
45 \\
42 \\
46\end{array}$ & $\begin{array}{l}3.01(1.39) \\
2.60(1.25) \\
2.52(1.28) \\
2.83(1.24)\end{array}$ \\
\hline
\end{tabular}

Note : Data on percentages is presented for three categories by collapsing the five-joint scale: (a) positive ('very great' \& 'great'); (b) medium ('some extent'); (c) negative ('little' \& 'very little').

The mean scores are based on the five-point scale where 1 'very little' $\ldots .5$ 'very great'.

Table 2. Rankings of Parties to which Social Workers are Currently and Prefer to be Accountable

\begin{tabular}{lcc}
\hline Party & $\begin{array}{c}\text { Currently } \\
\text { Accountable to }\end{array}$ & $\begin{array}{c}\text { Prefer to be } \\
\text { Accountable to }\end{array}$ \\
\hline 1. Client & 3 & 1 \\
2. Social service director & 1 & 2 \\
3. Physician & 4 & 5 \\
4. Peer & 6 & 3 \\
5. Administration & 2 & 4 \\
6. PSRO & 5 & 6 \\
7. Professional organization & 8 & 8 \\
8. Third party & 7 & 7 \\
\hline
\end{tabular}

$N=106$ (The above rankings are based on mean scores of respondents' ranking on the eight parties. Mean scores of rankings ranged from 2.1 to 7.2 , where 1 is most accountable to. 8 is least accountable to.) 